\title{
Efficacy and safety of pulmonary application of corticosteroids in preterm infants with respiratory distress syndrome: a systematic review and meta- analysis
}

\author{
Mahin Delara, ${ }^{1,2}$ Bhupendrasinh F Chauhan, ${ }^{1,3,4}$ Mê-Linh Le, ${ }^{5}$ Ahmed M Abou-Setta, ${ }^{6,7}$ \\ Ryan Zarychanski, ${ }^{6,7,8,9}$ Geert W' 'tong ${ }^{1,10}$
}

\begin{abstract}
- Additional material is published online only. To view please visit the journal online (http://dx.doi.org/10.1136/ archdischild-2017-314046).

For numbered affiliations see end of article.
\end{abstract}

\section{Correspondence to} Professor Geert W'tJong, Clinical Research Unit, Children's Hospital Research Institute of Manitoba, Winnipeg, MB R3E 3P4, Canada; geert.tjong@umanitoba.ca

This research was presented in the $33 \mathrm{rd}$ International Conference on Pharmacoepidemiology and Therapeutic Risk Management, Montreal, Canada, 26-30 August 2017. MD also received poster award in the 13th Annual Child Health Research Days, Winnipeg, Canada, 3-5 October 2017

Received 1 September 2017 Revised 6 March 2018 Accepted 10 March 2018 Published Online First 17 April 2018
Check for updates

To cite: Delara M, Chauhan BF, Le M-L, et al. Arch Dis Child Fetal Neonatal Ed 2019;104:F137-F144.

\section{ABSTRACT}

Background Systemic corticosteroids as the frontline treatment of respiratory distress syndrome (RDS) in preterm infants are associated with adverse effects on growth and neurodevelopmental outcome, but the pulmonary administration of steroids may help prevent the development of bronchopulmonary dysplasia (BPD) without these side effects.

Objectives To evaluate the efficacy and safety of pulmonary application of corticosteroids in preterm infants with RDS.

Methods MEDLINE, EMBASE, Cochrane Central Register of Controlled Trials, ClinicalTrials.gov, the WHO's International Clinical Trials Registry and grey literature were searched with no restriction on date and language of publication from inception to May 2016. Using a random-effect model, we pooled data from randomised controlled trials (RCTs) comparing inhaled or endotracheal corticosteroids with the standard of care, placebo or no other intervention in preterm infants with RDS.

Results We identified 873 potential citations and included 12 unique RCTs. Pulmonary corticosteroid therapy was associated with a significant reduction in the composite outcome of BPD or death (relative risk (RR) $0.85,95 \% \mathrm{Cl} 0.76$ to 0.96 ). Pulmonary application of corticosteroids significantly reduced the incidence of patent ductus arteriosus (PDA) (RR 0.82, 95\% Cl 0.74 to 0.92 ) and pneumonia (RR $0.57,95 \% \mathrm{Cl} 0.35$ to 0.92). There was no evidence of a significant difference regarding the risk of neurodevelopmental impairment or other side effects.

Conclusions Pulmonary administration of corticosteroids reduces the incidence of BPD or death, pneumonia, PDA without causing any major side effects in preterm infants with RDS.

\section{INTRODUCTION}

Preterm birth, defined as childbirth occurring before completed 37 weeks gestational age (GA), ${ }^{1}$ is reported in $11.1 \%$ of all births; or almost 15 million births per year worldwide. ${ }^{2}$ Nearly 1 million deaths in 2015 were caused by preterm birth complications including respiratory distress syndrome (RDS). ${ }^{3}$ Eight to $35 \%$ of RDS survivors develop $\mathrm{BPD}$, defined as oxygen dependency at 36 weeks postmenstrual age or 28 days postnatal age. ${ }^{4-9}$ BPD

\section{What is already known on this topic?}

- Several treatments have been evaluated to prevent bronchopulmonary dysplasia (BPD) in preterm infants with respiratory distress syndrome (RDS).

- Systemic corticosteroids as the frontline treatment are associated with adverse effects on growth and neurodevelopmental outcome.

- Pulmonary administration of steroids may help prevent the development of BPD without these side effects.

\section{What does this study add?}

- Pulmonary administration of corticosteroids could significantly reduce the risk of bronchopulmonary dysplasia or death, pneumonia and patent ductus arteriosus.

- No major side effects were found in preterm infants with RDS.

is a common complication in 50\% of extremely preterm neonates and is caused by ongoing lung injury and simultaneous repair. ${ }^{10}{ }^{11}$ Prenatal and postnatal infections, prolonged mechanical ventilation, supplemental oxygen and poor nutrition also contribute to lung fibrosis and arrested lung development in infants with BPD. ${ }^{11}{ }^{12}$ BPD is one of the leading causes of morbidity and mortality in preterm infants and is associated with neurodevelopmental impairment and respiratory problems later in life. ${ }^{1314}$

Management consists of respiratory support using oxygen supplementation, ventilation, application of surfactant and administration of systematic corticosteroids, which were widely used in the past. ${ }^{15-17}$ Among systematic corticosteroids, dexamethasone with dosing ranging from 0.1 to $0.5 \mathrm{mg} /$ $\mathrm{kg} /$ day and duration ranging from 3 to 42 days was considered as the most potent one. ${ }^{18}$ Betamethasone, a stereoisomer of dexamethasone has been administered at similar doses and was as effective as dexamethasone. ${ }^{19}$ With similar genomic effects but less potent than these two synthetic steroids, hydrocortisone was used as a natural hormone for BPD. ${ }^{18}$ 
Systematic corticosteroids possessed strong anti-inflammatory properties $^{20}$ and improved pulmonary compliance and resistance as well as gas exchange. ${ }^{21}$ This improvement facilitated the removal of the infant from ventilation and reduced the risk of BPD but caused serious short-term and long-term adverse effects including hypertension, hyperglycaemia, intestinal perforation, impaired growth and cerebral cortical matter. ${ }^{22} 23$ Immune suppression and the associated risk of infection, together with protein catabolism were implicated in the pathogenesis of these side effects. ${ }^{24-26}$

In recent years, use of steroids for the prevention of BPD has resurfaced as a therapeutic strategy, but following the development of local (pulmonary) application strategies to prevent the adverse effects of systemic exposure. ${ }^{27}$ The modalities are (1) inhalation and (2) intratracheal instillation. Beclomethasone comes as the most commonly used inhalational steroid. Budesonide and fluticasone have been also administered as topical corticosteroids. ${ }^{19}$ Budesonide was recently evaluated as intratracheal instillation with or without surfactant as a vehicle. However, the efficacy and safety of corticosteroids administered in preterm infants via these modalities are not well established.

We conducted a systematic review to identify, critically appraise and meta-analyse data from randomised controlled trials (RCTs) comparing the pulmonary application of corticosteroids (inhaled or intratracheal instillation) with standard treatment, placebo or no intervention in preterm infants with established clinical and radiologic evidence of RDS.

\section{METHODS}

We used an a priori protocol (CRD42016042985) and conducted this systematic review in accordance with the Methodological Expectations of Cochrane Intervention Reviews (MECIR) guidelines $^{28}$ and reported as per the Preferred Reporting Items for Systematic Reviews and Meta-analysis (PRISMA) guidelines. ${ }^{29}$

\section{Eligibility criteria}

We included RCTs evaluating preterm infants (GA $<37$ weeks irrespective of their birth weight) diagnosed with established RDS (using clinical, radiological or author-defined evidence). Corticosteroids were to be administered locally to the respiratory tract at any postnatal age, dose, timing or frequency compared with standard treatment (oxygen therapy and/or surfactant), placebo or no other intervention. The main a priori exclusion criteria were trials that exclusively evaluated infants with congenital anomalies or lethal cardiopulmonary disorders which are the leading cause of infant mortality ${ }^{30}$ and can distort the apparent treatment effect. We also excluded studies with cross-over, cluster or quasi-RCTs, non-randomised trials and observational studies including cohort and case-control studies. We chose RCTs since they are known as the best design to obtain unbiased estimates of treatment effect by controlling for both known and unknown confounders affecting the outcome. ${ }^{31}$

The primary efficacy outcomes were the incidence of BPD, all-cause mortality reported at the longest follow-up and the composite outcome of BPD or death. Since the criteria to define BPD still lack uniformity, we reported the composite outcome for both the earliest clinical definition of BPD as oxygen dependency at 28 days and the modified one as the need for oxygen therapy at 36 weeks corrected GA. ${ }^{32}$ To prevent misclassification in further analysis, we just focused on the second definition.

Secondary efficacy outcomes were pulmonary function tests, hospital lengths of stay and duration of mechanical ventilation. Safety outcomes were adverse effects including growth and

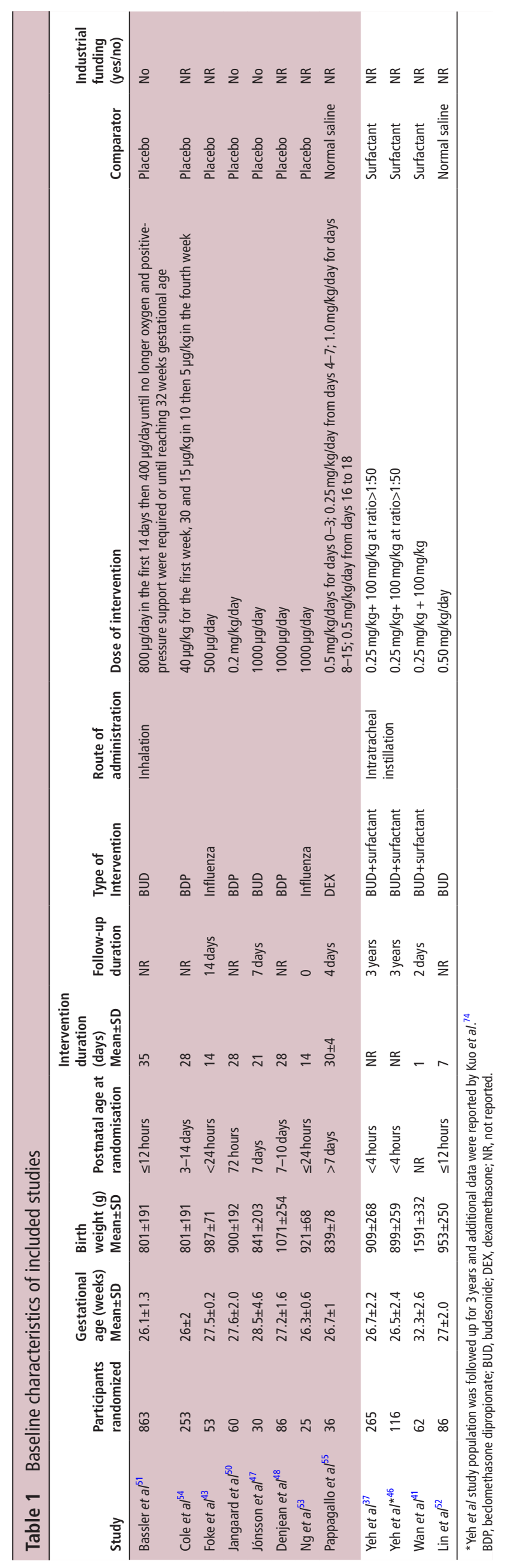




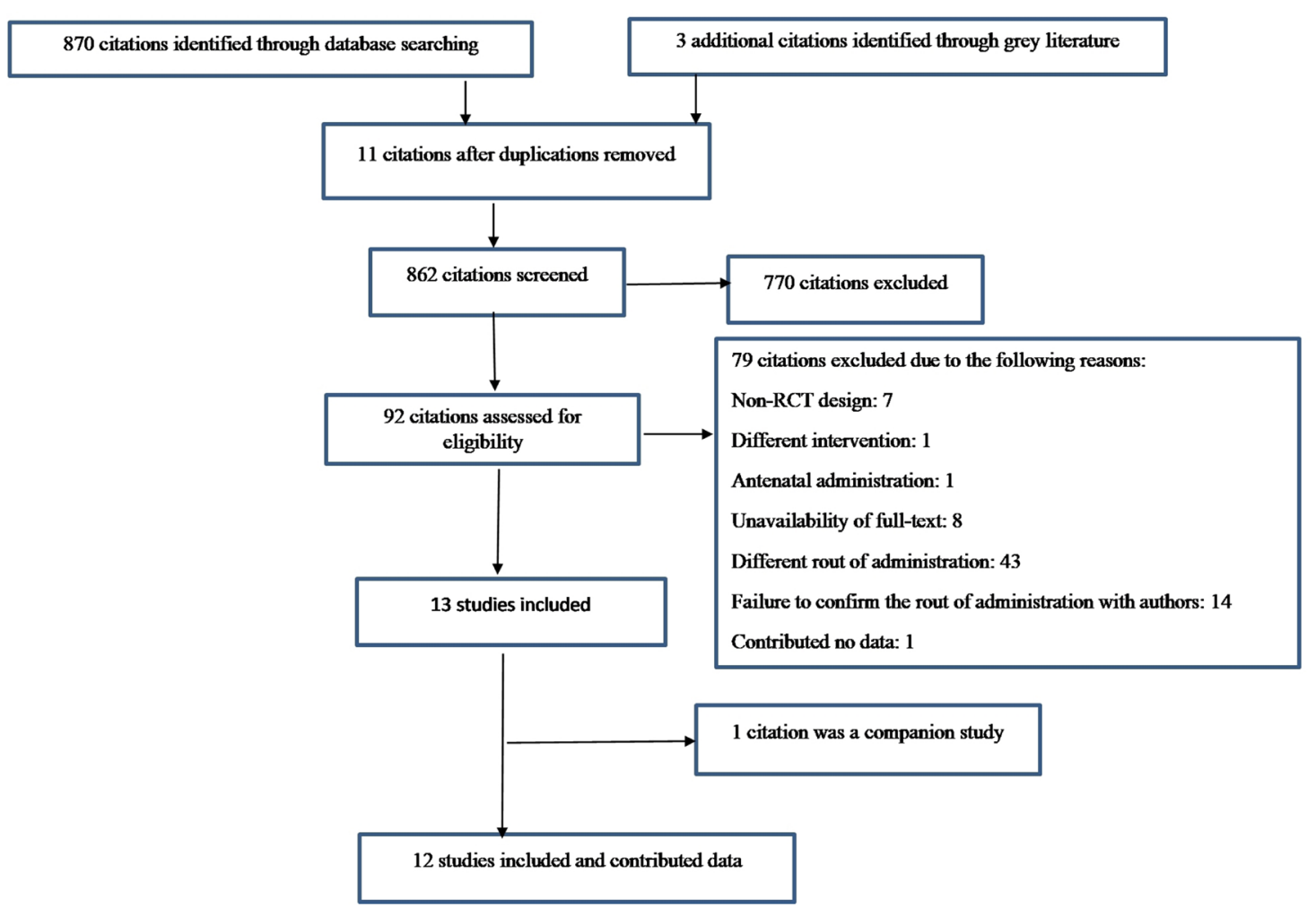

Figure 1 Preferred Reporting Items for Systematic Reviews and Meta-analysis flow chart depicting the selection process of included studies. RCT, randomised controlled trial.

neurodevelopmental impairment, retinopathy of prematurity, brain injury including intraventricular/periventricularhaemorrhage, necrotising enterocolitis, patent ductus arteriosus (PDA), hormonal axis depression, clinical sepsis and other infections.

\section{Search strategy and study selection}

We searched MEDLINE (Ovid), EMBASE (Ovid), Global Health Conferences (Ovid), International Pharmaceutical Abstracts (Ovid) and The Cochrane Central Register of Controlled Trials (CENTRAL-Wiley) from inception to May 2016. Individualised search strategies were used for each database without any date or language limits. The MEDLINE and EMBASE search strategies are presented in online supplementary appendix 1 . To identify ongoing trials, we searched ClinicalTrials.gov and the WHO's International Clinical Trials Registry. Conference abstracts were searched in Web of Science Core CollectionConference Proceedings. Reference lists of relevant narrative and systematic reviews and included trials were hand-searched for relevant citations. Reference management and citation screening were performed using EndNote (V.X7). ${ }^{33}$ Using a two-step process for study selection, two of three reviewers (MD, BC, GJ) independently screened title and abstract of each citation to determine whether a study met the broad inclusion criteria. The full-text of all relevant citations were retrieved for formal review. Two reviewers (MD, GJ) independently assessed the full-text reports. Conflicts were resolved by discussion between reviewers.

\section{Data extraction and management}

We used a standardised, piloted data extraction form. Reviewers (MD, GJ) extracted data independently, using a standardised form, with conflicts resolved through consensus. Table 1 illustrates the baseline data extracted from each trial.

\section{Quality assessment}

We assessed the risk of bias of the included trials using the Cochrane Risk of Bias Tool. ${ }^{34} 35$ As illustrated in online supplementary appendix 2 , this tool consists of six domains and a categorisation of the overall risk of bias. We judged each separate domain as 'low risk', 'unclear risk' or 'high risk'. If one or more individual domains were assessed as having a 'high risk' of bias, the trial received the same classification; similarly, for 'unclear risk'.

\section{Data analysis}

We analysed the data from included studies using RevMan (V.5.3.5). ${ }^{36}$ Meta-analyses were performed using random effects. We used the Mantel-Hanzel models for binary outcomes and inverse variance for continuous outcomes. We expressed pooled continuous data as mean difference (MD) and dichotomous data as a relative risk (RR), with $95 \%$ CIs. We quantified heterogeneity-related variability by using the $\mathrm{I}^{2}$ statistic.

\section{Subgroup analyses}

We performed subgroup analyses based on route (inhalation vs intratracheal instillation with or without a vehicle), timing of administration (early vs late), type of corticosteroid, type of comparator (surfactant vs placebo vs normal saline) and location of study (North America vs elsewhere); methodological quality (low vs unclear risk of bias) and publication status (full-text or conference proceedings vs not published).

\section{RESULTS}

Of 873 citations, available for review, we retrieved and reviewed full-text reports for 92 potentially eligible trials. Of these, we included 12 primary trials in this systematic review (figure 1). 


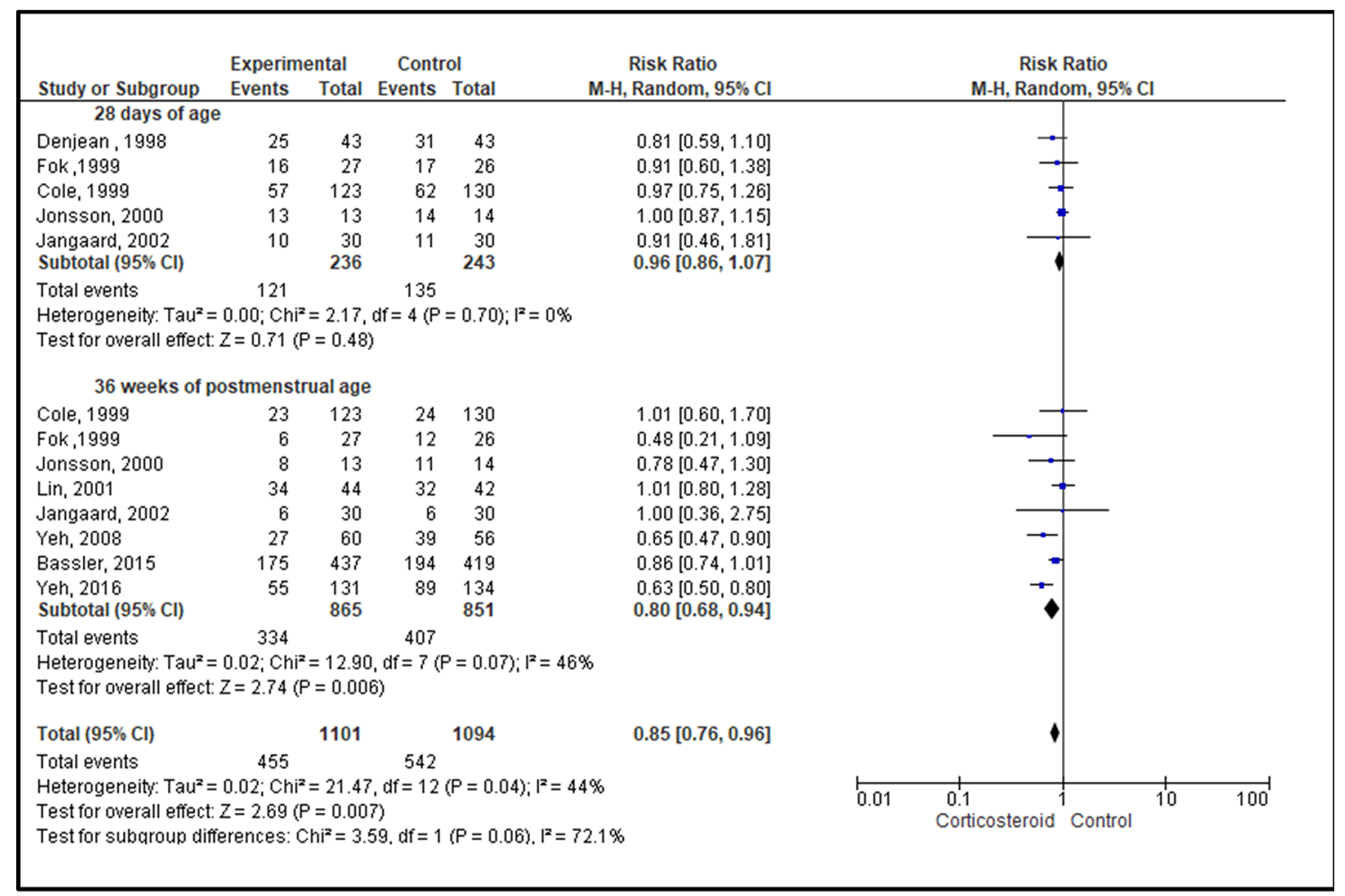

Each study is depicted by a point estimate represented by a square (box), the size of which corresponds to the weight of the study in the overall estimate represented by a diamond at the bottom of the graph. The error bars (horizontal lines) on either side of each square and the width of the diamond indicates the $95 \%$ confidence interval (CI) of the risk ratio (RR) estimates. The RRs are analyzed with the random- effects model and the heterogeneity across pooled trials is presented as I-squared $\left(\mathrm{I}^{2)}\right.$. Summary findings falling on the left side of the graphs favour corticosteroid therapy, those falling on the right side favour the control group.

Figure 2 Bronchopulmonary dysplasia or death assessed at different timing frames.

Three studies were multicentre trials. ${ }^{37-39}$ Three trials were published in Italian, ${ }^{40}$ Mandarin ${ }^{41}$ or Korean, ${ }^{42}$ while the others were published in English. Infants were recruited between the first 4 hours and the 14th day of postnatal age. The GA of enrolled infants ranged from 26 to 34 weeks, and the birth weight ranged from 801 to $1591 \mathrm{~g}$. The details of the study intervention varied among studies (table 1). The duration of intervention ranged from 1 day to 35 days with a maximum follow-up duration of 3 years. All trials administered corticosteroids for the prevention of BPD either in the first 24 hours of life f $^{3843-46}$ or later. $^{3947-50}$ Type of corticosteroid used for intervention also varied among trials as follows: budesonide (six trials), ${ }^{374146475152}$ fluticasone propionate (two trials), ${ }^{5354}$ beclomethasone (three trials) ${ }^{4854}$ and dexamethasone (one trial). ${ }^{55}$ In eight trials, corticosteroids were administered by inhalation, ${ }^{43475153-55}$ and in four trials, ${ }^{37414652}$ they were given to infants via the endotracheal route. Three trials ${ }^{374146}$ used an animal-derived surfactant in the control group, two studies used normal saline $e^{5255}$ and seven studies used placebo $^{4748515354}$ as comparators. Timing of BPD assessment differed across studies. One trial reported BPD at 28 days of age, ${ }^{48}$ four trials reported this outcome at 36 weeks of postmenstrual/postconceptional age 37384546 and three trials used both timing frames for the diagnosis of BPD. ${ }^{39} 4350$ Mortality rate was reported at 28 days of age (two trials), ${ }^{39} 48$ weeks of postnatal age (six trials) ${ }^{37-39454650}$ and before discharge (one trial). ${ }^{43}$ One trial was adjudicated to be at low risk of bias, ${ }^{51}$ and the others were judged to be at unclear risk of bias ${ }^{3741464752-55}$ (see online supplementary appendix 2).

\section{Primary efficacy outcomes and subgroup analysis}

Pulmonary application of corticosteroids was associated with a significant reduction in the composite outcome of death or BPD (RR $0.85 ; 95 \%$ CI 0.76 to 0.96 ). This reduction remained significant and was greater when BPD was assessed at 36 weeks of postmenstrual GA (RR $0.80,95 \%$ CI 0.68 to 0.94 ; $\mathrm{I}^{2} 46 \%$; 8 trials) compared with 28 days of age (RR $0.96,95 \%$ CI 0.86 to $1.07 ; \mathrm{I}^{2} 0 \% ; 5$ trials) (figure 2). Meta-analysis of trials which assessed BPD at 36 weeks of postmenstrual age showed greater reduction in the composite outcome when corticosteroids were administered endotracheally using surfactant as a vehicle (RR $0.64,95 \%$ CI 0.53 to $0.77 ; I^{2} 0 \% ; 2$ trials, 381 infants) compared with inhaled administration (RR $0.86,95 \%$ CI 0.75 to 0.98 ; $\mathrm{I}^{2} 0 \%$; 5 trials, 1249 infants) (figure 3). In contrast, direct instillation of corticosteroids without surfactant in one trial increased the incidence of death or BPD by 1\% (RR 1.01, $95 \mathrm{CI} \% 0.80$ to $1.28 ; 86$ infants). The pooled data from these trials also showed a significant reduction in the incidence of BPD or death in infants exposed to budesonide (RR $0.79,95 \%$ CI 0.65 to 0.95 ; I ${ }^{2} 62 \%$; 5 trails; 1350 infants) compared with beclomethasone (RR 1.01, $95 \%$ CI 0.64 to $1.60 ; \mathrm{I}^{2} 0 \% ; 2$ trials, 313 infants) and fluticasone (RR 0.48, 95\% CI 0.21 to 1.09; 1 trail, 53 infants) (figure 4).

Pulmonary application of corticosteroids had no effect on the incidence of death from all causes at 36 weeks of postnatal age (RR $0.99 ; 95 \%$ CI 0.75 to 1.30 ; I $\mathrm{I}^{2} 18 \%$; 6 trials; 1636 infants) (see online supplementary appendix 3). The longest follow-up for short-term mortality was 35 days with a median of 17.5 days 


\begin{tabular}{|c|c|c|c|c|c|c|c|c|c|}
\hline \multirow{2}{*}{$\frac{\text { Study or Subgroup }}{\text { Inhaled }}$} & \multicolumn{2}{|c|}{ Experimental } & \multicolumn{2}{|c|}{ Control } & \multirow{2}{*}{$\begin{array}{c}\text { Risk Ratio } \\
\text { M-H, Random, } 95 \% \mathrm{Cl} \\
\end{array}$} & \multirow{2}{*}{\multicolumn{4}{|c|}{$\begin{array}{c}\text { Risk Ratio } \\
\text { M-H, Random, } 95 \% \mathrm{Cl}\end{array}$}} \\
\hline & Events & Total & \multicolumn{2}{|c|}{ Events Total } & & & & & \\
\hline Fok,1999 & 6 & 27 & 12 & 26 & $0.48[0.21,1.09]$ & & & & \\
\hline Cole, 1999 & 23 & 123 & 24 & 130 & $1.01[0.60,1.70]$ & & - & 一 & \\
\hline Jonssan, 2000 & 8 & 13 & 11 & 14 & $0.78[0.47,1.30]$ & & $\rightarrow$ & & \\
\hline Jangaard, 2002 & 6 & 30 & 6 & 30 & $1.00[0.36,2.75]$ & & & & \\
\hline $\begin{array}{l}\text { Bassler, } 2015 \\
\text { Subtotal }(95 \% \mathrm{Cl})\end{array}$ & 175 & $\begin{array}{l}437 \\
630\end{array}$ & 194 & $\begin{array}{l}419 \\
619\end{array}$ & $\begin{array}{l}0.86[0.74,1.01] \\
0.86[0.75,0.98]\end{array}$ & & 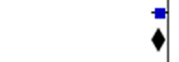 & & \\
\hline \multicolumn{10}{|c|}{$\begin{array}{l}\text { Heterogeneity: } \mathrm{Tau}^{2}=0.00 ; \mathrm{Chi}^{2}=2.53, \mathrm{df}=4(\mathrm{P}=0.64) ; \mathrm{l}^{2}=0 \% \\
\text { Test for overall effect: } Z=2.19(\mathrm{P}=0.03)\end{array}$} \\
\hline \multicolumn{10}{|c|}{ Intratracheal instillation } \\
\hline $\begin{array}{l}\text { Lin, } 2001 \\
\text { Subtotal }(95 \% \mathrm{Cl})\end{array}$ & 34 & $\begin{array}{l}44 \\
44\end{array}$ & 32 & $\begin{array}{l}42 \\
42\end{array}$ & $\begin{array}{r}1.01[0.80,1.28] \\
1.01[0.80,1.28]\end{array}$ & & 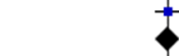 & & \\
\hline \multicolumn{10}{|c|}{$\begin{array}{l}\text { Heterogeneity: Not applicable } \\
\text { Test for overall effect: } Z=0.12(P=0.91)\end{array}$} \\
\hline \multicolumn{10}{|c|}{ Intratracheal instillation using a vehicle } \\
\hline Yeh, 2008 & 27 & 60 & 39 & 56 & $0.65[0.47,0.90]$ & & $\rightarrow$ & & \\
\hline $\begin{array}{l}\text { Yeh, } 2016 \\
\text { Subtotal }(95 \% \mathrm{Cl})\end{array}$ & 55 & $\begin{array}{l}131 \\
191\end{array}$ & 89 & $\begin{array}{l}134 \\
190\end{array}$ & $\begin{array}{l}0.63[0.50,0.80] \\
0.64[0.53,0.77]\end{array}$ & & $\vec{\forall}$ & & \\
\hline \multicolumn{10}{|c|}{$\begin{array}{l}\text { Total events } \quad 82 \quad 128 \\
\text { Heterogeneity: Tau }=0.00 ; \mathrm{Chi}^{2}=0.01, \mathrm{df}=1(\mathrm{P}=0.92) ; \mathrm{I}^{2}=0 \% \\
\text { Test for overall effect: } Z=4.63(\mathrm{P}<0.00001)\end{array}$} \\
\hline Total $(95 \% \mathrm{Cl})$ & & 865 & & 851 & $0.80[0.68,0.94]$ & & $\bullet$ & & \\
\hline Total events & 334 & & 407 & & & & & & \\
\hline $\begin{array}{l}\text { Heterogeneity: Tau } \\
\text { Test for overall effect } \\
\text { Test for subqroup dit }\end{array}$ & $\begin{array}{l}0.02 ; \mathrm{Chi} \\
Z=2.74 \\
\text { erences: }\end{array}$ & $\begin{array}{l}=12.90 \\
=0.00 \\
h i^{2}=10\end{array}$ & $\begin{array}{l}d f=?(F \\
6) \\
.28 . d f=\end{array}$ & $\begin{array}{l}P=0.07 \\
2(P=0\end{array}$ & $80.6 \%$ & 0.01 & $\begin{array}{c}0.1 \\
\text { Corticosteroids }\end{array}$ & Control 10 & 100 \\
\hline
\end{tabular}

Each study is depicted by a point estimate represented by a square (box), the size of which corresponds to the weight of the study in the overall estimate represented by a diamond at the bottom of the graph. The error bars (horizontal lines) on either side of each square and the width of the diamond indicates the $95 \%$ confidence interval (CI) of the risk ratio (RR) estimates. The RRs are analyzed with the random- effects model and the heterogeneity across pooled trials is presented as I-squared $\left(\mathrm{I}^{2)}\right.$. Summary findings falling on the left side of the graphs favour corticosteroid therapy, those falling on the right side favour the control group.

Figure 3 Bronchopulmonary dysplasia or death at 36 weeks of postnatal age associated with different routes of pulmonary corticosteroid therapy among included trials.

after birth. The infants in the treatment group also had $27 \%$ reduction in the incidence of BPD at 36 weeks of postnatal age compared with the control group (RR 0.73 , 95\% CI 0.61 to 0.86 ; $\mathrm{I}^{2} 12 \%$; 6 trials; 1663 infants) (see online supplementary appendix 4).

Finally, the observed differences among subgroups on the timing of administration, type of corticosteroid, type of comparator, route of administration, publication status, the risk of bias and trial geography were not statistically significant (see online supplementary appendix 5).

\section{Secondary efficacy outcomes}

The pooled data from trials demonstrated no evidence of significant reduction in the value of fraction of inspired oxygen $\left(\mathrm{FIO}_{2}\right)$ levels, ${ }^{4147455}$ the infants' blood $\mathrm{PaO}_{2}$ of carbon dioxide $\left(\mathrm{PCO}_{2}\right)$ at latest measurement ${ }^{414752}$ and the duration of mechanical ventilation $^{48}$ in the treatment group compared with control group. Mean air pressure $e^{55}$ and $\mathrm{PaO}_{2}$ of oxygen $\left(\mathrm{PO}_{2}\right)^{41}$ as indicators of pulmonary function and duration of hospitalisation ${ }^{46}$ were reported in single trials (see online supplementary appendix 6).

\section{Safety outcomes}

Among five studies enrolling 1320 infants, we observed a significant reduction in the risk of PDA in those treated with pulmonary corticosteroids compared with the control group (RR 0.82 , $95 \%$ CI 0.74 to 0.92 ; $\left.\mathrm{I}^{2} 31 \%\right)$.
Additionally, pooled data from three studies 37414 enrolling 324 infants demonstrated a reduction in the risk of developing pneumonia in those treated with corticosteroid compared with control group (RR $0.57,95 \%$ CI 0.35 to 0.92 ; $\mathrm{I}^{2} 0 \%$ ).

The pooled data from trials also did not show any significant difference in groups with respect to short-term changes in weight (MD - 1.73, 95\% CI -14.04 to 10,$\left.58 ; \mathrm{I}^{2} 0 \%\right), 38750$ head circumference (MD $0.07,95 \% \mathrm{CI}-0.03$ to $\left.0.17 ; \mathrm{I}^{2} 0 \%\right)^{38} 4750$ and height (MD $-0.04,95 \%$ CI 0.18 to $\left.0.10 ; \mathrm{I}^{2} 41 \%\right){ }^{4750}$

Using the same definition for neurodevelopmental impairment, two trials reported this outcome after a follow-up of $2-3$ years ${ }^{3746}$ indicating that the risk of developing neurodevelopmental impairment in those treated with endotracheal budesonide using surfactant as a vehicle and those in the control group receiving surfactant alone was not significantly different $(\mathrm{n}=239$ infants, RR $1.01,95 \% \mathrm{CI} 0.68$ to 1.52 ; $\left.\mathrm{I}^{2} 0 \%\right)$.

No significant difference was observed between treatment and control groups on the following adverse outcomes: retinopathy of prematurity, brain injury including intraventricular/periventricular haemorrhage, necrotising enterocolitis and sepsis (see online supplementary appendix 7). Adverse effects including intestinal perforation, periventricular leukomalacia, hyperglycaemia, hypertension, pneumothorax, hormonal axis depression, gastrointestinal bleeding, oral candidiasis and meningitis were reported by single trials without any significant RR. 


\begin{tabular}{|c|c|c|c|c|c|c|c|c|c|c|c|}
\hline Study or Subgroup & \multicolumn{2}{|c|}{ Experimental } & \multicolumn{2}{|c|}{ Control } & \multirow[t]{2}{*}{$\begin{array}{c}\text { Risk Ratio } \\
\text { M-H, Random, } 95 \% \mathrm{Cl} \\
\end{array}$} & \multicolumn{6}{|c|}{$\begin{array}{c}\text { Risk Ratio } \\
\text { M-H, Random, } 95 \% \mathrm{Cl}\end{array}$} \\
\hline \multicolumn{11}{|c|}{ Beclomethasone } & \\
\hline Cole, 1999 & 23 & 123 & 24 & 130 & $1.01[0.60,1.70]$ & & & & - & & \\
\hline Jangaard, 2002 & 6 & $\begin{array}{r}30 \\
153\end{array}$ & 6 & 30 & $1.00[0.36,2.75]$ & & & & & & \\
\hline Subtotal $(95 \% \mathrm{Cl})$ & & 153 & & 160 & $1.01[0.64,1.60]$ & & & & & & \\
\hline Total events & 29 & & 30 & & & & & & & & \\
\hline \multirow{2}{*}{\multicolumn{12}{|c|}{$\begin{array}{l}\text { Heterogeneity: } \mathrm{Tau}^{2}=0.00 ; \mathrm{Chi}^{2}=0.00, \mathrm{df}=1(P=0.98) ;{ }^{2}=0 \% \\
\text { Test for averall effect: } Z=0.04(P=0.97)\end{array}$}} \\
\hline & & & & & & & & & & & \\
\hline \multicolumn{12}{|l|}{ Budesonide } \\
\hline Jonsson, 2000 & 8 & 13 & 11 & 14 & $0.78[0.47,1.30]$ & & & & - & & \\
\hline Lin, 2001 & 34 & 44 & 32 & 42 & $1.01[0.80,1.28]$ & & & & - & & \\
\hline Yeh, 2008 & 27 & 60 & 39 & 56 & $0.65[0.47,0.90]$ & & & - & & & \\
\hline Bassler, 2015 & 175 & 437 & 194 & 419 & $0.86[0.74,1.01]$ & & & $\Rightarrow-1$ & & & \\
\hline Yeh, 2016 & 55 & 131 & 89 & 134 & $0.63[0.50,0.80]$ & & & & & & \\
\hline Subtotal $(95 \% \mathrm{Cl})$ & & 685 & & 665 & $0.79[0.65,0.95]$ & & & & & & \\
\hline Total events & 299 & & 365 & & & & & & & & \\
\hline \multirow{2}{*}{\multicolumn{12}{|c|}{$\begin{array}{l}\text { Heterogeneity: } \mathrm{Tau}^{2}=0.03 ; \mathrm{Ch}^{2}=10.52, \mathrm{df}=4(\mathrm{P}=0.03) ; \mathrm{I}^{2}=62 \% \\
\text { Test for owerall effect: } Z=2.49(P=0.01)\end{array}$}} \\
\hline & & & & & & & & & & & \\
\hline \multicolumn{12}{|l|}{ Fluticasone } \\
\hline $\begin{array}{l}\text { Fok } 1999 \\
\text { Subtotal }(95 \% \mathrm{Cl})\end{array}$ & 6 & $\begin{array}{l}27 \\
27\end{array}$ & 12 & $\begin{array}{l}26 \\
26\end{array}$ & $\begin{array}{l}0.48[0.21,1.09] \\
0.48[0.21,1.09]\end{array}$ & & & & & & \\
\hline Total events & 6 & & 12 & & & & & & & & \\
\hline \multirow{2}{*}{\multicolumn{12}{|c|}{$\begin{array}{l}\text { Heterogeneity: Not applicable } \\
\text { Test for owerall effect: } Z=1.75(P=0.08)\end{array}$}} \\
\hline & & & & & & & & & & & \\
\hline Total $(95 \% \mathrm{Cl})$ & & 865 & & 851 & $0.80[0.68,0.94]$ & & & 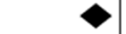 & & & \\
\hline Total events & 334 & & 407 & & & & & & & & \\
\hline \multicolumn{6}{|c|}{$\begin{array}{l}\text { Heterogeneity: } \mathrm{Tau}^{2}=0.02 ; \mathrm{Chi}^{2}=12.90, \mathrm{df}=7(\mathrm{P}=0.07) ; \mathrm{l}^{2}=46 \% \\
\text { Test for overall effect: } Z=2.74(P=0.006) \\
\text { Test for subqroup differences: } \mathrm{Chi}^{2}=2.49, \mathrm{df}=2(\mathrm{P}=0.29), \mathrm{I}^{2}=19.7 \%\end{array}$} & 0.1 & $\begin{array}{ll}0.2 \\
\text { Cort }\end{array}$ & $\begin{array}{c}0.51 \\
\text { icosteroids }\end{array}$ & $\begin{array}{l}1 \\
1 \\
\text { Control } \\
\end{array}$ & $\frac{1}{5}$ & $\sqrt{10}$ \\
\hline
\end{tabular}

Each study is depicted by a point estimate represented by a square (box), the size of which corresponds to the weight of the study in the overall estimate represented by a diamond at the bottom of the graph. The error bars (horizontal lines) on either side of each square and the width of the diamond indicates the $95 \%$ confidence interval (CI) of the risk ratio (RR) estimates. The RRs are analyzed with the random- effects model and the heterogeneity across pooled trials is presented as I-squared $\left(\mathrm{I}^{2)}\right.$. Summary findings falling on the left side of the graphs favour corticosteroid therapy, those falling on the right side favour the control group.

Figure 4 Bronchopulmonary dysplasia or death at 36 weeks of postnatal age associated with different types of pulmonary corticosteroid therapy among included trials.

\section{DISCUSSION}

A variety of systemic reviews has addressed the use of systemic, ${ }^{5657}$ or inhaled ${ }^{58-60}$ corticosteroids or a comparison of both routes of administration $^{22} 236162$ in the prevention or treatment of BPD. Due to a limited number of included studies, no firm conclusion could be obtained from these reviews. Additionally, there was a significant overlap in ages at the administration of the inhaled corticosteroids. ${ }^{22} 236063$ For instance, Shah et al conducted a meta-analysis of seven trials including 492 infants that were administered inhaled steroids before the age of 2 weeks, but the primary and secondary outcome variables were only reported in five trials. ${ }^{63}$ Similarly, Onland et al reported a meta-analysis of eight trials compromising of 232 infants who were administered inhaled corticosteroids after 7 days of age compared with a control group. ${ }^{60}$ However, both meta-analyses failed to find any significant differences in the incidence of mortality and BPD in infants treated with inhaled corticosteroids compared with those who received placebo. Another meta-analysis of three trials conducted by Shah et al. comparing inhaled and systemic corticosteroids also found no difference in the incidence of mortality and BPD. ${ }^{22}$ A recently published meta-analysis by Venkatraman et $a l^{64}$ showed a $43 \%$ reduction in BPD without affecting the mortality rate. This study included two trials investigating the endotracheal administration of budesonide in very low birth infants.

Our systematic review included more trials (12) representing 1935 infants and provided the evidence that pulmonary administration of corticosteroids significantly reduced the incidence of BPD and the composite outcome of death or BPD in preterm infants. The difference between routes of administration was significant, with a larger reduction when steroids were administered intratracheally using surfactant as a vehicle ${ }^{37} 46$ than inhalation. ${ }^{38} 39434750$ Even though our results are consistent with the findings of other meta-analyses 576465 that showed a significant decrease in the incidence of BPD and a decrease or no change in mortality, ours cannot be compared with some of them ${ }^{5765}$ as those reviews included only trials with systemic corticosteroid therapy, which as a different route may be associated with higher rate of adverse effects.

We also found that endotracheal instillation of corticosteroids alone did not significantly affect the incidence of the composite outcome of death or BPD but adding surfactant improved the findings. Surfactant is a surface-active lipoprotein complex (phospholipoprotein) that reduces the surface tension in the lungs to enhance $\mathrm{O}_{2} / \mathrm{CO}_{2}$ exchange. ${ }^{15-17}$ Using surfactant as a vehicle is based on a phenomenon known as the Marangoni Effect, wherein the dragging force created by surface tension gradients between surfactant and airway liquid facilitates drug distribution to the periphery of the lungs. ${ }^{66}$ Surfactant also re-expands atelectatic areas and leads to effective deposition of corticosteroids even in collapsed areas of lungs. ${ }^{67}$

Compared with other types of corticosteroids, the lower risk of death or BPD in infants who were exposed to budesonide can be related to the corticosteroids' effect on the synthesis of lamellar 
body phosphatidylcholine and increase in surfactant synthesis. ${ }^{68}$ With antiproliferative properties, corticosteroids can also affect lung fibroblasts, pulmonary vascular and bronchial smooth muscle cells. Moreover, budesonide is shown to increase the production of surfactant proteins gene transcription ${ }^{68} 69$ and surface active agents. $^{70-72}$

The pulmonary administration of corticosteroids also demonstrated beneficial effects on the incidence of PDA and pneumonia with no effect on growth, neurodevelopment and short-term mortality. However, well-designed RCTs with a long-term follow-up are needed to record these outcomes at a later age.

Our analysis is unique as it added a single very large trial that includes $66 \%$ more infants than all the studies above together and considered no limitation for a) the age of the infant being studied in trials by including preterm infants from birth onwards, b) severity of the condition and c) routes of pulmonary administration of corticosteroids. Accordingly, this systematic review provides useful practical information considering the role of pulmonary corticosteroids for preterm infants at risk of BPD with a large sample size of infants $(n=1935)$ and by considering both routes of administration, inhaled and endotracheal with or without using surfactant as a vehicle.

Additionally, this study is a comprehensive review including multiple electronic database searches, hand searching of grey literature and bibliographies of included studies and forward searching. Furthermore, in case of inadequate reporting of data or presentation of data in a different format, we could reach the authors, all responding and providing additional data. This review also provided a high quality of evidence as none of the included trials was at high risk of bias and all were free of reporting and other sources of bias. We also used a priori protocol which was prepared according to the PRISMA-P guideline of $2015 .^{73}$ We conducted the review by MECIR guidelines ${ }^{28}$ and reported the results following PRISMA guidelines for systematic review and meta-analysis. ${ }^{29}$

There are limitations of this systematic review that merit discussion. First, in most trials, the duration of post-treatment assessment was short (2-14 days). Only two trials reported neurologic outcomes, ${ }^{37} 46$ and other trials failed to follow-up enrolled preterm infants. To ensure that corticosteroids have a sustained benefit, evaluating long-term adverse effects is of high importance. Second, secondary outcomes of corticosteroid therapy could not be sufficiently assessed in this review because mean air pressure and $\mathrm{PO}_{2}$ as indicators of respiratory function and duration of hospitalisation were reported by single trials; therefore, they could not be included in the meta-analysis. Finally, the included studies were published between 1992 and 2017, and significant changes in the management of preterm infants with RDS have taken place over three decades. Due to these concerns, the generalisability of the findings and our ability to make treatment recommendations regarding the application of inhaled or endotracheal corticosteroids in the current era of RDS management is limited. To address these limitations, a large RCT is needed to evaluate the risk-benefit ratio of pulmonary corticosteroid therapy. We also could not assess publication bias due to a limited number of included studies for desired outcomes.

\section{CONCLUSION}

Pulmonary administration of corticosteroid therapy significantly decreases the risk of BPD alone and the composite outcome of death or BPD in preterm infants with RDS. Direct intratracheal instillation of corticosteroids using surfactant as a vehicle is significantly more effective than inhaled corticosteroids to treat preterm infants with RDS. The pulmonary application of corticosteroids also has beneficial effects on pneumonia and PDA with no effect on growth, neurodevelopment and short-term mortality, which warrants further evaluation with longer follow-up.

\section{Author affiliations}

'Clinical Research Unit, Children's Hospital Research Institute of Manitoba, Winnipeg, Manitoba, Canada

${ }^{2}$ College of Human Ecology, Faculty of Health Sciences, University of Manitoba, Winnipeg, Manitoba, Canada

${ }^{3}$ College of Pharmacy, Faculty of Health Sciences, University of Manitoba, Winnipeg, Manitoba, Canada

${ }^{4}$ Soham Research Group Inc, Winnipeg, Manitoba, Canada

${ }^{5}$ Neil John Maclean Health Sciences Library, University of Manitoba, Winnipeg, Manitoba, Canada

${ }^{6}$ George \& Fay Yee Centre for Healthcare Innovation, University of Manitoba/ Winnipeg Regional Health Authority, Winnipeg, Manitoba, Canada

${ }^{7}$ Department of Community Health Sciences, University of Manitoba, Winnipeg, Manitoba, Canada

${ }^{8}$ Department of Internal Medicine, Section of Critical Care, University of Manitoba, Winnipeg, Manitoba, Canada

${ }^{9}$ Department of Haematology and Medical Oncology, Cancer Care Manitoba, Winnipeg, Manitoba, Canada

${ }^{10}$ Department of Pediatrics, Max Rady College of Medicine, Rady Faculty of Health Sciences, University of Manitoba, Winnipeg, Manitoba, Canada

Contributors GWt' proposed the topic. MD and M-LL designed the search strategy. MD, GWt'J and BFC reviewed the citations and extracted the data. AMA-S and RZ checked the methodology. MD analysed the data and prepared the first draft of the manuscript. All authors were involved in revising the manuscript and approved the final version.

Funding No funding was specifically obtained for this systematic review.

Competing interests MD's salary is supported by GW'tJ's Establishment Grant from the University of Manitoba and the Children's Hospital Research Foundation of Manitoba. RZ is the recipient of a Canadian Institutes of Health Research (CIHR) New Investigator salary award.

Patient consent Not required.

Provenance and peer review Not commissioned; externally peer reviewed.

(c) Article author(s) (or their employer(s) unless otherwise stated in the text of the article) 2019. All rights reserved. No commercial use is permitted unless otherwise expressly granted.

\section{REFERENCES}

1 Beck S, Wojdyla D, Say L, et al. The worldwide incidence of preterm birth: a systematic review of maternal mortality and morbidity. Bull World Health Organ 2010;88:31-8.

2 Blencowe $\mathrm{H}$, Cousens $\mathrm{S}$, Oestergaard MZ, et al. National, regional, and worldwide estimates of preterm birth rates in the year 2010 with time trends since 1990 for selected countries: a systematic analysis and implications. Lancet 2012;379:2162-72.

3 Organization WH. Preterm bith: fact sheet. 2016. http://www.who.int/mediacentre/ factsheets/fs363/en/

4 Askie LM, Henderson-Smart DJ, Jones RA. Management of infants with chronic lung disease of prematurity in Australasia. Early Hum Dev 2005;81:135-42.

5 Kotecha S. Management of infants with chronic lung disease of prematurity in various parts of the world. Elsevier 2005.

6 Lemons JA, Bauer CR, Oh W, et al. Very low birth weight outcomes of the National Institute of Child health and human development neonatal research network, January 1995 through December 1996. NICHD Neonatal Research Network. Pediatrics 2001;107:e1.

7 Li J, Wei K. Management of infants with chronic lung disease of prematurity in China. Early Hum Dev 2005;81:151-4.

8 Palomino MA, Morgues M, Martínez F. Management of infants with chronic lung disease of prematurity in Chile. Early Hum Dev 2005;81:143-9.

9 Shaw NJ, Kotecha S. Management of infants with chronic lung disease of prematurity in the United Kingdom. Early Hum Dev 2005;81:165-70.

10 Jobe AH. What is BPD in 2012 and what will BPD become? Early Hum Dev 2012;88:S27-S28.

11 Baraldi E, Filippone M. Chronic lung disease after premature birth. N Eng/ J Med 2007;357:1946-55.

12 Jobe AH. What is BPD in 2012 and what will BPD become? Early Hum Dev 2012;88 Suppl 2:S27-S28.

13 Doyle LW, Anderson P, Callanan C. Respiratory function at age 8-9 years in extremely low birthweight/very preterm children born in Victoria in 1991-1992. Pediatr Pulmonol 2006;41:570-6. 
14 Vom Hove M, Prenzel F, Uhlig HH, et al. Pulmonary outcome in former preterm, very low birth weight children with bronchopulmonary dysplasia: a case-control follow-up at school age. J Pediatr 2014;164:e44:40-5.

15 Guardia CG, Moya FR, Sinha S, et al. A pharmacoeconomic analysis of in-hospital costs resulting from reintubation in preterm infants treated with lucinactant, beractant, or poractant alfa. J Pediatr Pharmacol Ther 2012;17:220-7.

16 Schwartz RM, Luby AM, Scanlon JW, et al. Effect of surfactant on morbidity, mortality, and resource use in newborn infants weighing 500 to 1500 g. N Engl J Med 1994;330:1476-80.

17 Maniscalco WM, Kendig JW, Shapiro DL. Surfactant replacement therapy: impact on hospital charges for premature infants with respiratory distress syndrome. Pediatrics 1989;83:1-6.

18 Jobe AH. Postnatal corticosteroids for bronchopulmonary dysplasia. Clin Perinatol 2009;36:177-88.

19 Gupta S, Prasanth K, Chen CM, et al. Postnatal corticosteroids for prevention and treatment of chronic lung disease in the preterm newborn. Int J Pediatr 2012;2012:1-12.

20 Kugelman A, Durand M. A comprehensive approach to the prevention of bronchopulmonary dysplasia. Pediatr Pulmonol 2011;46:1153-65.

21 Ballard PL, Ballard RA. Scientific basis and therapeutic regimens for use of antenatal glucocorticoids. Am J Obstet Gynecol 1995;173:254-62.

22 Shah SS, Ohlsson A, Halliday HL, et al. Inhaled versus systemic corticosteroids for preventing chronic lung disease in ventilated very low birth weight preterm neonates. Cochrane Database Syst Rev 2012:CD002058

23 Shah SS, Ohlsson A, Halliday HL, et al. Inhaled versus systemic corticosteroids for the treatment of chronic lung disease in ventilated very low birth weight preterm infants. Cochrane Database Syst Rev 2012:CD002057.

24 Brownlee KG, Ng PC, Henderson MJ, et al. Catabolic effect of dexamethasone in the preterm baby. Arch Dis Child 1992:67:1-4.

25 Yeh TF, Lin YJ, Hsieh WS, et al. Early postnatal dexamethasone therapy for the prevention of chronic lung disease in preterm infants with respiratory distress syndrome: a multicenter clinical trial. Pediatrics 1997;100:e3.

26 Nimmo AJ, Carstairs JR, Patole SK, et al. Intratracheal administration of glucocorticoids using surfactant as a vehicle. Clin Exp Pharmacol Physiol 2002;29:661-5.

27 Gupta S, Sinha SK, Donn SM. Myth: mechanical ventilation is a therapeutic relic. Seminars in Fetal and Neonatal Medicine 2011;16:275-8.

28 Chandler J, Churchill R, Higgins J, et al. Methodological standards for the conduct of new Cochrane Intervention Reviews. Sl: Cochrane Collaboration 2013.

29 Moher D, Liberati A, Tetzlaff J, et al. Preferred reporting items for systematic reviews and meta-analyses: the PRISMA statement. PLoS Med 2009;6:e1000097.

30 Dastgiri S, Gilmour WH, Stone DH. Survival of children born with congenital anomalies. Arch Dis Child 2003;88:391-4.

31 Kao LS, Tyson JE, Blakely ML, et al. Clinical research methodology I: introduction to randomized trials. J Am Coll Surg 2008;206:361-9.

32 Davidson LM, Berkelhamer SK. Bronchopulmonary dysplasia: chronic lung disease of infancy and long-term pulmonary outcomes. J Clin Med 2017;6:4.

33 End note. A Smarter Way to Research. 2017. http://endnote.com

34 Higgins JP, Green S. Cochrane handbook for systematic reviews of interventions. Vol 4: John Wiley \& Sons 2011.

35 Higgins JP, Altman DG, Gøtzsche PC, et al. The Cochrane Collaboration's tool for assessing risk of bias in randomised trials. BMJ 2011;343:d5928

36 community C. Reviwe Manager 5: Review Manager 5 (RevMan 5) is the software used for preparing and maintaining Cochrane Reviews. 2014. http://community.cochrane. org/tools/review-production-tools/revman-5

37 Yeh TF, Chen CM, Wu SY, et al. Intratracheal Administration of Budesonide/Surfactant to Prevent Bronchopulmonary Dysplasia. Am J Respir Crit Care Med 2016:193:86-95.

38 Bassler D, Plavka R, Shinwell ES, et al. Early Inhaled Budesonide for the Prevention of Bronchopulmonary Dysplasia. N Eng/ J Med Overseas Ed 2015;373:1497-506.

39 Cole CH, Colton T, Shah BL, et al. Early inhaled glucocorticoid therapy to prevent bronchopulmonary dysplasia. N Engl J Med Overseas Ed 1999;340:1005-10.

40 Romagnoli C, Vento G, Zecca E, et al. A controlled trial of dexamethasone in preterm infants at risk of chronic lung disease. Rivista Italiana Di Pediatria-italian Journal Of Pediatrics 1998;24:283-8.

41 Wan Jun LH, Li L, Shi-xia LIN. Study on combining budesonide Suspension, pulmonary surfactant curosurf and nasal continious positive airway pressure in treatment of respiratory distress syndrom of premature. Pharmaceutical Biotechnology 2010:17:434-7

42 Shim SY, Cho SJ, Park E. Prevention of chronic lung disease with early dexamethasone treatment in less than 32 weeks premature: randomized controlled study. Korean Journal of Pediatrics 2004;47:521-6.

43 Fok TF, Lam K, Dolovich M, et al. Randomised controlled study of early use of inhaled corticosteroid in preterm infants with respiratory distress syndrome. Arch Dis Child Fetal Neonatal Ed 1999:80:F203-F208.

44 PC N, Fok TF, Wong GW, et al. Pituitary-adrenal suppression in preterm, very low birth weight infants after inhaled fluticasone propionate treatment. The Journal of clinical endocrinology and metabolism 1998;83:2390-3.
45 Lin YJ, Lin HC, Lin CH, et al. Early endotracheal instillatin (El) of budesonide (Bd) for prevention of CLD in preterm infants with RDS - a double blind clinical trial. Pediatric research 2001;49:278a.

46 Yeh TF, Lin HC, Chang $\mathrm{CH}$, et al. Early intratracheal instillation of budesonide using surfactant as a vehicle to prevent chronic lung disease in preterm infants: a pilot study. Pediatrics 2008:121:e1310-8.

47 Jónsson B, Eriksson M, Söder 0 , et al. Budesonide delivered by dosimetric jet nebulization to preterm very low birthweight infants at high risk for development of chronic lung disease. Acta Paediatr 2000;89:1449-55.

48 Denjean A, Paris-Llado J, Zupan V, et al. Inhaled salbutamol and beclomethasone for preventing broncho-pulmonary dysplasia: a randomised double-blind study. Eur J Pediatr 1998;157:926-31.

49 Pappagallo M, Abbasi S, Bhutan VK. Respiratory and systemic effects of inhaled dexamethasone on ventilator dependant preterm infants at risk for bronchopulmonary dysplasia. The Indian Journal of Pediatrics 1998:65:273-82.

50 Jangaard KA, Stinson DA, Allen AC, et al. Early prophylactic inhaled beclomethasone in infants less than $1250 \mathrm{~g}$ for the prevention of chronic lung disease. Paediatr Child Health 2002;7:13-19.

51 Bassler D, Plavka R, Shinwell ES, et al. Early Inhaled Budesonide for the Prevention of Bronchopulmonary Dysplasia. N Engl J Med 2015;373:1497-506.

52 Lin Y, Lin H, Lin C, et al. Early endotracheal instillation of budesonide (B) for prevention of CLD in preterm infant with RDS-a double blind clinical trial. Ped Res 2001;49 278A.

$53 \mathrm{Ng} \mathrm{PC}$, Fok TF, Wong GW, et al. Pituitary-adrenal suppression in preterm, very low birth weight infants after inhaled fluticasone propionate treatment. J Clin Endocrinol Metab 1998:83:2390-3.

54 Cole $\mathrm{CH}$, Colton T, Shah BL, et al. Early inhaled glucocorticoid therapy to prevent bronchopulmonary dysplasia. N Eng/ J Med 1999:340:1005-10.

55 Pappagallo M, Abbasi S, Bhutani VK. Respiratory and systemic effects of inhaled dexamethasone on ventilator dependant preterm infants at risk for bronchopulmonary dysplasia. Indian J Pediatr 1998;65:273-82.

56 Halliday HL, Ehrenkranz RA, Early DLW. It; 8 days) postnatal corticosteroids for preventing chronic lung disease in preterm infants. The Cochrane Library 2009.

57 Halliday HL, Ehrenkranz RA, Late DLW. gt; 7 days) postnatal corticosteroids for chronic lung disease in preterm infants. The Cochrane Library 2009.

58 Shah VS, Ohlsson A, Halliday HL, et al. Early administration of inhaled corticosteroids for preventing chronic lung disease in ventilated very low birth weight preterm neonates. The Cochrane Library 2007

59 Lister P, lles R, Shaw BNj, et al. Withdrawn: Inhaled steroids for neonatal chronic lung disease. Cochrane Database Syst Rev 2010:CD002311.

60 Onland W, Offringa M, Late vanKA. $\geq 7$ days) inhalation corticosteroids to reduce bronchopulmonary dysplasia in preterm infants. The Cochrane Library 2012.

61 Shah S, OhIsson A, Halliday H, et al. Inhaled versus systemic corticosteroids for the treatment of chronic lung disease in ventilated very low birth weight preterm infants. The Cochrane Library 2003.

62 Shah SS, Ohlsson A, Halliday HL, et al. Inhaled versus systemic corticosteroids for the treatment of chronic lung disease in ventilated very low birth weight preterm infants. The Cochrane Library 2007.

63 Shah VS, Ohlsson A, Halliday HL, et al. Early administration of inhaled corticosteroids for preventing chronic lung disease in ventilated very low birth weight preterm neonates. The Cochrane Library 2012.

64 Venkataraman R, Kamaluddeen M, Hasan SU, et al. Intratracheal administration of budesonide-surfactant in prevention of bronchopulmonary dysplasia in very low birth weight infants: a systematic review and meta-analysis. Pediatr Pulmonol 2017:52:968-75.

65 Shah V, Ohlsson A. Postnatal dexamethasone in the prevention of chronic lung disease. Recent Advances in Paediatrics 2001;19:77-96.

66 Adamson AW, Gast AP. Physical chemistry of surfaces. 1967.

67 Haitsma JJ, Lachmann U, Lachmann B. Exogenous surfactant as a drug delivery agent. Adv Drug Deliv Rev 2001;47:197-207.

68 Mendelson CR, Boggaram V. 9 Hormonal and developmental regulation of pulmonary surfactant synthesis in fetal lung. Baillière's Clinical Endocrinology and Metabolism 1990;4:351-78.

69 Z-W Y, Zhang J-H. Effect of inhaled budesonide on surfactant protein expression in asthmatic mice: Allergy and Asthma Proceedings. 2008.

70 Yang CF, Jeng MJ, Soong WJ, et al. Acute pathophysiological effects of intratracheal instillation of budesonide and exogenous surfactant in a neonatal surfactant-depleted piglet model. Pediatr Neonatol 2010;51:219-26.

71 Stewart AG, Fernandes D, Tomlinson PR. The effect of glucocorticoids on proliferation of human cultured airway smooth muscle. Br J Pharmacol 1995:116:3219-26.

72 Roth M, Johnson PR, Borger P, et al. Dysfunctional interaction of C/EBPalpha and the glucocorticoid receptor in asthmatic bronchial smooth-muscle cells. N Engl J Med 2004:351:560-74.

73 Moher D, Shamseer L, Clarke M, et al. Preferred reporting items for systematic review and meta-analysis protocols (PRISMA-P) 2015 statement. Syst Rev 2015;4:1.

74 Kuo HT, Lin HC, Tsai CH, et al. A follow-up study of preterm infants given budesonide using surfactant as a vehicle to prevent chronic lung disease in preterm infants. J Pediatr 2010;156:537-41. 